\title{
Chinese Collective Trolling
}

\author{
Honglei Sun \\ School of Information Management, Nanjing University, \\ China
}

\author{
Pnina Fichman \\ Rob Kling Center for Social Informatics, School of \\ Informatics, Computing, and Engineering, Indiana University
}

\begin{abstract}
The vast majority of research on online trolling focused on Western cultures. Given the role context plays in shaping online interactions, it is important to take into account its socio-cultural context and investigate the role of national culture, by conducting research into trolling in Eastern cultures. In this paper, we attempt to begin addressing this gap by focusing on Chinese collective trolling, looking at Sina Weibo's PG One case. Specifically, we aim to identify who are the major players, what are the metaphors they use, and what are the major trolling tactics employed in Chinese collective trolling event. Using a mixed-method approach, we analyzed 2,004 posts and 9,967 comments on Sina Weibo's PG One case, of which 480 were sampled for thematic content analysis. Major contributions of this study include an account of collective trolling in Chinese cultural context that is characterized by role switching between trolls, bystanders, and victims during the various stages of the event. We conclude with suggestion for future research directions.
\end{abstract}

\section{KEYWORDS}

Online trolling, reverse trolling, collective trolling, China, collective action, Sina Weibo, Chinese online subculture

\section{INTRODUCTION}

Trolling can be defined as set of diverse context-dependent online behaviors that are pseudo-sincere, intentional, provocative and repetitive. Online trolling has become an increasingly pervasive and dynamic phenomenon in online communities (Fichman \& Sanfilippo, 2016). Scholars described it as a context-dependent (e.g., Fichman \& Sanfilippo, 2015; Herring, Job-Sluder, Scheckler, \& Barab, 2002; Sanfilippo, Yang \& Fichman, 2017), intentional (Hardaker, 2010; Shachaf \& Hara, 2008), provocative (Hardaker, 2010), and repetitive (Fichman \& Sanfilippo, 2016; Suler, 2004) behavior by an individual toward other individuals or groups (Fichman \& Sanfilippo, 2016). Phillips (2015) noticed cross-national diversity of online trolling and mentioned various motivations of trolling behaviors in Australia, Britain and the US respectively. Fichman and Sanfilippo (2016) call for more research on the complex socio-cultural relationships between culture and trolling.

Yet, most of the literature refer to online trolling cases in the context of Western cultures. While online trolling in Eastern cultural context, such as China, began attracting scholarly attention (e.g., de Seta's, 2013; Yang, et al., 2017; Yang \& Fichman, 2017), it is still unclear whether trolling behaviors exist in Chinese online communities, and how Chinese collectivistic culture might play into online trolling. Further, since Chinese Internet context is unique and characterized by the Great Firewall, it is possible that trolling in this context have distinct characteristics compared to online trolling in Western context. Given the role context plays in shaping socio-technical interactions (Kling, 2007), it is important to consider the contextual impact when studying online trolling (Sanfilippo, Fichman, \& Yang, 2017). Thus, it is necessary to gain a better understanding of online trolling in various socio-cultural contexts and not to overlook trolling manifestation in Eastern cultures. In this paper, we conduct a study of collective trolling in China, focusing on Sina Weibo's PG One case study. We aim to identify 1) who are the major players; 2) what are the metaphors they use; and 3) what are the major trolling tactics they employ in this collective trolling event. The paper structure is as follows: First, we provide a brief background and related work on online trolling, and then we describe our method, along with a description of our data. Next, we discuss our case analysis, answering the three research questions, and we conclude with discussion and suggestion for future research.

\section{BACKGROUND}

\section{Internet and Sina Weibo use in China}

Based on the latest report from the China Internet Network Information Center (2018), there are 751 million users in China (as of June, 2017), accounting for one fifth of the total number of Internet users in the world. The Internet penetration rate in China reached 55\%, exceeding the global average by $4.6 \%$ (CNNIC, 2018). Furthermore, due to Internet censorship in China, known as "Great Firewall", many Western popular social network platforms, such as Facebook and Twitter, are blocked in mainland China (Ensafi, et al., 2015). Instead, Chinese users use the Sina Weibo platform - a Twitter-like website - to chat and share information with other users. One of the obvious difference between social network sites in China compared with the West is the lack of anonymity on Chinese platforms, while on some Western platforms, users are anonymous. On these western platforms, users can interact online without revealing who they are, where they come from, how old are they, and so on. However, on all Chinese social media platforms, all users online accounts are connected to their real-life ID. Even when users use various 
online usernames and try to disguise their real identities, age, and gender, the Chinese authorities can track their activities. This context clearly has an effect on norms of behaviors on Chinese social media platforms.

Sina Weibo is a popular social media site with over 361 million monthly active users and 159 million average daily active users (Noonan, 2017). The platform is currently the dominant microblogging service provider in China (Lin et al., 2013) and a major source of commentary on a wide range of topics. For example, about 100 million messages are posted daily on Sina Weibo (Jiang, Wang, Tsou, \& Fu, 2015). On Sina Weibo, a user may post, mention, or talk to other people using "@UserName", add hashtags with "\#HashName\#”, follow other users to make their posts appear in one's own timeline, repost with "//@UserName" (similar to Twitter's retweet function "RT @UserName"), select posts for one's favorites list, and verify the account, when the user is a celebrity. Just like on Twitter, there are also "VIP" accounts on Sina Weibo, which are called "verified users" and have a yellow "V" sign after their names. These verified users attract thousands of followers, creating "celebrity-centric" social networks on Sina Weibo, which play an important role in disseminating latest events, controversial opinions and breaking news (Wang, Lei, \& Xu, 2015). Most verified users are influential people offline as well, and many are public figures, celebrities, or organizations' accounts. The major difference from Twitter is that Sina Weibo is used almost exclusively by Chinese language speakers (Jiang, Wang, Tsou, \& Fu, 2015). In order to evade the multiple levels of Sina Weibo censorship, many Chinese netizens use clever methods to elude the suppression, for example posting images instead of more easily censored text or using memes (Sullivan, 2014).

\section{Online trolling}

As online trolling increased in pervasiveness, the term is used as an umbrella term for different phenomena, from serious and deviant to humorous or ideological driven behavior (Sanfilippo, Fichman, \& Yang, 2018); it is context-dependent phenomena (Fichman \& Sanfilippo, 2015). Trolling is associated with direct aggression, flaming, spraying, and even cyber bullying (Hardakar, 2010; de Seta, 2013). Perceptions of trolling varies between perpetrators, victims, bystanders, scholars, the media, and the public at large. On one hand, trolls often justify their behaviors ideologically or by the high moral disengagement experienced with respect to their online activities (Suler \& Phillips 1998), while on the other hand, scholars and the media often frame trolling as unjustifiable and depraved acts (Bishop 2014).

While trolling behaviors varies widely, the literature emphasizes deviant and negative behaviors, which have many commonalities with flaming (e.g., Hardaker, 2010; Herring, Job-Sluder, Scheckler, \& Barab, 2002) and hacking (e.g., Shachaf \& Hara, 2010; Suler \& Phillips, 1998). Fichman and Sanfilippo (2016) emphasize that "not all trolling is equal" and claim that trolling is more complicated than mere deviant behavior leading to negative impact, and recent scholarly works began to describe lighthearted, humorous, or ideological trolling (e.g., Phillips \& Milner, 2017; Sanfilippo, Fichman \& Yang, 2018). Because online trolling is a socio-technical phenomenon, with context-dependent manifestation that varies from one community to another and from one platform to another, it may exhibit different behavioral patterns in different countries (Fichman \& Sanfilippo, 2016), and more specifically, its manifestation in China may be more collectivistic than trolling in Western cultures (Yang \& Fichman, 2017). Thus, by using a mixed method analysis of Sina Weibo PG One's case to identify behavioral patterns of collective trolling, that flourish under the Chinese firewall, this paper aims to extend our understanding of online trolling in context. Specifically, we aim to identify who are the major players, what are the metaphors they use, and what are the major trolling tactics employed in this Chinese collective trolling event.

\section{METHOD}

We employed a mixed method approach and analyzed 2,004 posts and 9,967 comments on Sina Weibo, of which 480 were sampled for content analysis. The event of interest in our case study of Chinese collective trolling occurred in January 2018 and is referred to as PG One in this paper. PG One is the nickname of Wang Hao (王昊), one of China's best-known rappers, whose victory on The Rap of China competition brought him over four million followers on Sina Weibo platform (Fan, 2018). As part of the method section, we first describe the setting, PG One case study, and then follow with the description of our data collection and analysis.

\section{PG One case study}

The PG One case study illustrated an example of Chinese collective trolling on Sina Weibo that was observed during the time period of Jan. $7^{\text {th }}, 20187$ p.m. to Jan. $8^{\text {th }}, 20185$ a.m. (China Time). The event of interest to our case study started when some Sina Weibo users criticized one of his songs for containing degrading and out-of-line lyrics (Jiayun, 2018). Then, a magazine published by the central government, known as the Tower of Violet Light (TVL), and the Communist Youth League ${ }^{1}$, continued posting and harshly criticizing the dark lyrics of PG One another song, "Christmas Eve", for encouraging teenagers to use drugs and insulting women. TVL also added two photos of a few lines from the lyrics of the song "Christmas Eve", to represent the

\footnotetext{
${ }^{1}$ The Communist Youth League is a youth movement of the P. R. China for youth between the ages of fourteen and twenty-eight, run by the Communist Party of China (CPC).
} 
song's general spirit. PG One's fans (PGF) learned about TVL's posts on Sina Weibo, and a group of his fans, who misunderstood TVL to be the name of a restaurant, planned a revenge. Their revenge plan (which was based on their misunderstanding of TVL to be a restaurant name) included spreading cockroaches in the "restaurant". Their plan also included a negative campaign on a popular e-commerce site in China, Taobao, against the restaurant, claiming that the restaurant, TVL, uses sewer sludge skimmed oil for cooking, posting "Gutter Oil of TVL". At this point, around 6 p.m. on Jan. 7, 2018 (China Time), a microblogger (Xiaojiananfang), who was a member of PGF's QQ (an instant messaging software service) task-force group, posted the plan of the PGF QQ group chat on Sina Weibo. Following this post, the PGF plan, known now as "Gutter Oil of TVL", became viral and turned into a trending search topic on Sina Weibo on January 8, 2018 (China Time). The trending search topic increasingly attracted users' attention and Sina Weibo platform had been flooded with thousands of posts and comments over a 10 hours period. We collected all the Sina Wiebo's PG One case study posts during this event for our analysis.

\section{Data collection \& analysis}

We collected posts that were a part of this 10 hours event on Sina Weibo on Jan. $7^{\text {th }}, 20187$ p.m. to Jan. $8^{\text {th }}, 20185$ a.m. (China Time). The basic dataset consists of 2,872 posts that had the keywords “Gutter Oil of TVL” (紫光阁地沟油), in chronological order, and 9,967 comments replying to these posts. Table 1 and Figure 1 describe the dataset, distribution of posts and comments as of Jan. 8, 2018, 5 a.m. (China Time).

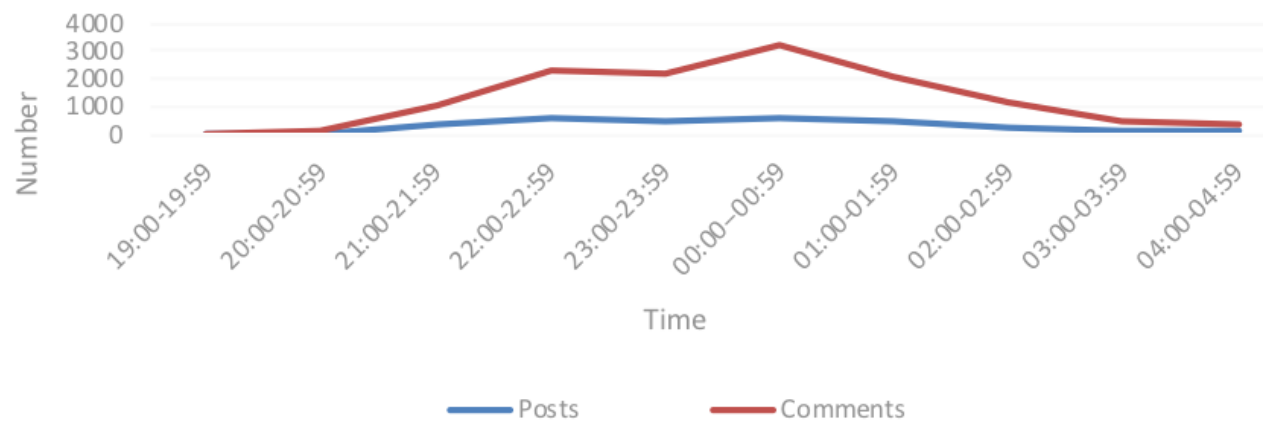

Figure 1. Distribution of posts and comments during the event

\begin{tabular}{|c|c|c|c|c|c|c|c|c|c|c|}
\hline $\begin{array}{c}\text { Number of pots and com- } \\
\text { ments per hour }\end{array}$ & $\begin{array}{c}19: 00- \\
19: 59\end{array}$ & $\begin{array}{c}20: 00- \\
20: 59\end{array}$ & $\begin{array}{c}21: 00- \\
21: 59\end{array}$ & $\begin{array}{c}22: 00- \\
22: 59\end{array}$ & $\begin{array}{c}23: 00- \\
23: 59\end{array}$ & $\begin{array}{c}00: 00-- \\
00: 59\end{array}$ & $\begin{array}{c}01: 00- \\
01: 59\end{array}$ & $\begin{array}{c}02: 00- \\
02: 59\end{array}$ & $\begin{array}{c}03: 00- \\
03: 59\end{array}$ & $\begin{array}{c}04: 00- \\
04: 59\end{array}$ \\
\hline Posts & 2 & 29 & 351 & 610 & 439 & 617 & 445 & 215 & 87 & 77 \\
\hline Comments & 1 & 90 & 672 & 1656 & 1728 & 2634 & 1629 & 897 & 360 & 301 \\
\hline
\end{tabular}

Table 1. Posting frequency during the event

Since the dataset is relatively large, and the distribution of posts is irregular, we designed a two-stage sampling process with non-probability at each and employed a judgment sampling strategy. This judgement sampling method uses purposeful criteria in choosing the sample, to include cases that have the most strategic position to provide the information needed (Sekaran \& Boogie, 2010); it is based on our own judgements about the representative posts (Kothari, 1990). Although we were well aware of its limitations in representing the event, this method was applied in the selection of the posts since we felt that the sample selected could serve the research purpose better (Köksal, \& Riddle, 2007).

Based on posting frequencies, we identified 5 primary segments of time periods: the first two hours were merged into one segment, the first stage, and the last 4 hours were merged into one stage, the last stage. Each stage stands for a particular turning point of the event as follow: Stage 1: earliest posts; Stage 2: First peak - turning into hottest search topics; Stage 3: Maintain momentum; Stage 4: Peak; Stage 5: Calm down.

\begin{tabular}{|c|c|c|c|c|c|}
\hline Time period & Event stages & $\begin{array}{c}\text { Numbers of posts, } \\
\text { comments \& chats } \\
\text { per min }\end{array}$ & $\begin{array}{c}\text { Number of } \\
\text { posts sam- } \\
\text { pled }\end{array}$ & $\begin{array}{c}\text { Number of } \\
\text { comments } \\
\text { sampled }\end{array}$ & $\begin{array}{c}\text { Number of } \\
\text { chats sampled }\end{array}$ \\
\hline 19:00-21:59 & Stage 1: Earliest posts & 2.03 & 12 & 46 & 16 \\
\hline 22:00-22:59 & $\begin{array}{c}\text { Stage 2: First peak - turning } \\
\text { into hottest search topics }\end{array}$ & 37.77 & 18 & 91 & 13 \\
\hline 23:00-23:59 & Stage 3: Maintain momentum & 36.12 & 17 & 68 & 12 \\
\hline 00:00-00:59 & Stage 4: Peak & 54.18 & 18 & 84 & 9 \\
\hline
\end{tabular}




\begin{tabular}{|l|l|l|l|l|l|}
\hline 01:00-04:59 & Stage 5: Calm down & 16.75 & 15 & 51 & 10 \\
\hline & Total & 20.40 & 80 & 340 & 60 \\
\hline
\end{tabular}

Table 2. Five stages sample

We found that many posts and comments added some screenshots of PGF group chats, which were included in our sample due to their informative nature. This sample includes a total of 480 posts: 80 posts, 340 comments, and 60 chats from the five segments was used in our content analysis (Table 2).

We designed a codebook, with 5 categories (stakeholder group, trolling role, content, and trolling tactic) and 49 codes. Codes were derived from prior work on trolling (Sanfilippo, Yang, \& Fichman, 2017b), which we continuously revised during the coding process, adding codes that originated from our data.

We manually coded and analyzed the samples from these five stages using open coding (Corbin \& Strauss, 2014). Coding was conducted at the level of individual posts by the first author and a second coder coded a subset of the data to ensure coding reliability. Inter-coder reliability was high, at $82.5 \%$ of agreement.

\section{FINDINGS}

This section includes three parts as we aim to identify 1) who are the major players; 2) what are the metaphors they use; and 3) what are the major trolling tactics employed in Chinese collective trolling event.

\section{1) Major players}

A few stakeholder groups were involved in our collective trolling event. Stakeholders switched their roles during the event between trolls, bystanders, and victims of trolls. We labeled posters group affiliation as one of the following four stakeholder groups: 1) PG One's Fans (PGF); 2) Tower of Violet Light (TVL); 3) General Participants (GP), those who lack other group affiliation; or 4) Verified users (VIP), those who typically hold a celebrity status. Based on self-proclaimed identity and the context of each post, we also assigned to each user one of three roles: 1) troll; 2) bystander; or 3) victim. Table 3 presents the number of posts by group in each stage that reveals the event pattern: an ephemeral but aggressive post-flood that increased quickly in a short time dominated by GP. This group, GP, generated most of the posts, overwhelming the other stakeholder groups during each of the five stages. PGF's and TVL's posting pattern have both a small-scale fluctuation pattern; for PGF the peak is in the first stage, and for TVL in the third stage, while VIP exhibit a decreased posting pattern as the event progressed.

\begin{tabular}{|c|c|c|c|c|}
\hline $\begin{array}{c}\text { Posts by stakeholder } \\
\text { groups at stage }\end{array}$ & $\begin{array}{c}\text { PGF } \\
\text { Number of posts } \\
\text { (percent of posts at } \\
\text { stage out of all PGF } \\
\text { posts) }\end{array}$ & $\begin{array}{c}\text { TVL } \\
\text { Number of posts } \\
\text { (percent of posts at } \\
\text { stage out of all TVL } \\
\text { posts) }\end{array}$ & $\begin{array}{c}\text { GP } \\
\text { Number of posts } \\
\text { (percent of posts at } \\
\text { stage out of all GP } \\
\text { posts) }\end{array}$ & $\begin{array}{c}\text { Vumber of posts } \\
\text { (percent of posts at } \\
\text { stage out of all VIP } \\
\text { posts) }\end{array}$ \\
\hline Stage 1: Earliest posts & $22(35.48 \%)$ & $0(0 \%)$ & $46(12.17 \%)$ & $13(33.33 \%)$ \\
\hline $\begin{array}{c}\text { Stage 2: First peak-turning } \\
\text { into hottest search topics }\end{array}$ & $12(19.35 \%)$ & $0(0 \%)$ & $95(25.13 \%)$ & $14(35.90 \%)$ \\
\hline $\begin{array}{c}\text { Stage 3: Maintain momen- } \\
\text { tum }\end{array}$ & $11(17.74 \%)$ & $1(100 \%)$ & $83(21.96 \%)$ & $6(15.38 \%)$ \\
\hline Stage 4: Peak & $10(16.13 \%)$ & $0(0 \%)$ & $87(23.02 \%)$ & $5(12.82 \%)$ \\
\hline Stage 5: Calm down & $7(11.29 \%)$ & $0(0 \%)$ & $67(17.72 \%)$ & $1(2.56 \%)$ \\
\hline
\end{tabular}

Table 3. Posts by stakeholder groups in Five stages $(\mathrm{N}=480)$

Table 4 provides the distribution of posts from each of the four stakeholder groups by each of the three trolling roles. At the beginning, PGF planned to troll the TVL, but later PGF became the target-group, which was trolled by TVL and thousands of GP users. As is shown in Table 4, PGF, GP, VIP all played more than one role during the entire event, they switched roles between trolls, bystanders, and victims of trolls.

\begin{tabular}{|c|c|c|c|c|}
\hline $\begin{array}{c}\text { Stakeholder groups } \\
\text { by trolling roles }\end{array}$ & $\begin{array}{c}\text { PGF } \\
\text { Number of posts } \\
\text { (percent of posts by } \\
\text { role and stakeholder } \\
\text { out of total posts) }\end{array}$ & $\begin{array}{c}\text { TVL } \\
\text { Number of posts } \\
\text { (percent of posts by } \\
\text { role and stakeholder } \\
\text { out of total posts) }\end{array}$ & $\begin{array}{c}\text { GP } \\
\text { Number of posts } \\
\text { (percent of posts by } \\
\text { role and stakeholder } \\
\text { out of total posts) }\end{array}$ & $\begin{array}{c}\text { Vumber of posts } \\
\text { (percent of posts by } \\
\text { role and stakeholder } \\
\text { out of total posts) }\end{array}$ \\
\hline Trolls & $41(8.54 \%)$ & $0(0.00 \%)$ & $166(34.58 \%)$ & $18(3.75 \%)$ \\
\hline Victims & $15(3.13 \%)$ & $1(0.21 \%)$ & $12(2.50 \%)$ & $0(0.00 \%)$ \\
\hline
\end{tabular}




\begin{tabular}{|c|c|c|c|c|}
\hline Bystanders & $6(1.25 \%)$ & $0(0.00 \%)$ & $200(41.67 \%)$ & $21(4.38 \%)$ \\
\hline
\end{tabular}

Table 4. Posts of stakeholder groups by trolling roles $(\mathrm{N}=480)$

\section{The trolls}

In this event, all stakeholder groups trolled at one point or another. At first, PGF were planning a revenge by a collective trolling campaign. In past events, the PGF group was involved in a well-organized and well-planned actions in support and admiration of PG One; these events lasted a couple of hours or days. The plan was to spread cockroaches into what they believed to be a restaurant, who criticized their idol, PG One, and to follow up by posting online about it. They had also planned to employ water-army ${ }^{2}$ to post about TVL's terrible cooking practices, using the idea of "Gutter Oil of TVL". However, before PGF took action, their plan had leaked out, and they became the target of collective trolling. Toward the end of the event, PGF turned into the main trolling target in reverse-trolling by TVL, GP as well as VIP; most of the trolling at this point have been posted by GP.

\section{Bystanders}

The bystander role includes mainly GP and VIP accounts. While the GP group trolled the most and have been trolled the most of all four stakeholder groups, most of them played a bystander role during the entire event. The VIP, in addition to retweeting TVL's post, which reported on the PGF trolling plan, some VIP also added self-mockery posts and trolled the PGF. For example, The Communist Youth League (VIP account) posted jokingly: "Would their next exposed target be the small workshop that sells green rice balls? Afraid. JPG". In fact, VIP users played an important role in accelerating the development of this event by broadcasting it to their followers and by simply reacting to it. For instance, at 08:45 p.m. on January 7, 2018 (China Time), a well-known microblogger, Hacker Kevin, posted a post that was reposted thousands of times and generated 9,511 reaction comments. With the development of the event, more and more bystanders engaged in trolling PGF, together forming a viral group trolling; these bystanders turned into trolls and were engaged in this collective trolling event.

\section{The victims}

The victim role was played by TVL, PGF, and GP users. TVL at first was mistakenly confused to be a restaurant, was the target of the PGF trolling, as it was criticized for "Using gutter oil", "Brand Deception", and "Eat cockroaches in the food!". However, at 11:30 p.m. on January 7, 2018 (China Time), TVL made one post that self-mockingly described itself as a scared baby, who was too "weak, poor, and helpless" to fight with PGF, as they were neither ignoring posts related to "Gutter Oil of TVL", nor clarifying their position; instead they, as a scared baby, only hide in their dining room and kept shivering. This same post also mocked PGF users as if they were pretending to be asleep. This post reversed TVL's role from being trolled by PGF to reversetrolling PGF, turning PGF into victims. This TVL post was reposted thousands of times and pushed this trolling "war" to its peak, when PGF was the new target of trolling.

\section{2) Content}

The thematic components of the posts and comments help us understand this collective trolling action better. Table 5 presents the top 5 topics and metaphors in each stakeholder groups' posts. There were four interesting metaphors: 1) this event was metaphorically referred to as “war" (战争); 2) participants who supported TVL were referred to as “The friendly army” (友 军); 3) participants who supported PGF were referred to as “The enemy” (敌军); and 4) participants who watched the trolling event unfolding were referred to as “Onlooker” (吃瓜群众), a group of bystanders.

The most frequently posted metaphor was "the friendly army", as most posts and comments claimed their support of TVL or opposing PGF and indicating that they were the friendly army. Examples for the friendly army metaphor include: "Come on, baby purple” (加油, 紫宝宝), referring to the literal meaning of TVL, Tower of Violet Light, and “Must ban this cult” (封杀 这种邪教), referring to PGF as a cult of PG One fans . Interestingly, not all of the trolls trolled directly, as many of them, specifically GP users, intentionally pretended to be members of PGF group. They pseudo sincerely condemned "Gutter Oil of TVL" or supported PGF, adding a dog's head emoticon to mean the opposite, and that they actually supported TVL instead. Users who post or comment added a dog's head emoticon (sa) at the end of their comment to indicate that they are part of the friendly army, and thus expressing exactly the opposite meaning. For instance, a user posted the following: "Let's get together as PGF, and I can drive you to the mental hospital” (各位万友一定要团结起来, 抱成团, 我送你们去精神病院 ${ }^{a}$ ), to mock PGF as mentally ill users. Some users enjoyed making fun of “the enemy”(敌军) when referring to PGF while adding a smiley face emoticon (3) to indicate the joke. For example, "We just want to ban PG One, but his fans want to kill him 9 " (我们只是想封杀他, 没想到他的粉丝是想弄死他 ). Some “onlookers”, a group of bystanders, claimed that they simply

\footnotetext{
${ }^{2}$ Water-army refer to online paid ghost posters in China; it is typically composed of a large number of people, who are well organized to "flood" the Internet with purposeful comments and articles.
} 


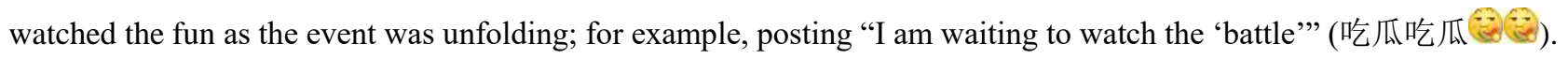

\begin{tabular}{|c|c|c|c|c|c|}
\hline $\begin{array}{l}\text { Most fre- } \\
\text { quent con- } \\
\text { tent by } \\
\text { stakeholder } \\
\text { groups }\end{array}$ & $\begin{array}{c}\text { PGF } \\
\text { (percent of content } \\
\text { out of all PGF con- } \\
\text { tents) }\end{array}$ & $\begin{array}{c}\text { TVL } \\
\text { (percent of con- } \\
\text { tent out of all } \\
\text { TVL contents) }\end{array}$ & $\begin{array}{c}\text { GP } \\
\text { (percent of con- } \\
\text { tent out of all GP } \\
\text { contents) }\end{array}$ & $\begin{array}{c}\text { VIP } \\
\text { (percent of content } \\
\text { out of all VIP con- } \\
\text { tents) }\end{array}$ & $\begin{array}{c}\text { Overall } \\
\text { (percent of content } \\
\text { out of all contents) }\end{array}$ \\
\hline 1 & $\begin{array}{c}\text { Whitewashing PG } \\
\text { One(23.68\%) }\end{array}$ & $\begin{array}{l}\text { "Gutter oil of } \\
\text { TVL" (50\%) }\end{array}$ & $\begin{array}{l}\text { The friendly } \\
\text { army (25.14\%) }\end{array}$ & $\begin{array}{l}\text { Reporting this } \\
\text { event }(12.50 \%)\end{array}$ & $\begin{array}{l}\text { The friendly } \\
\text { army }(20.56 \%)\end{array}$ \\
\hline 2 & $\begin{array}{c}\text { Transferring } \\
\text { Target }(19.74 \%)\end{array}$ & $\begin{array}{l}\text { The friendly } \\
\text { army (50\%) }\end{array}$ & $\begin{array}{l}\text { Attacking PGF or } \\
\text { PG One }(12.48 \%)\end{array}$ & $\begin{array}{l}\text { Response to } \\
\text { PGF's action } \\
\qquad(12.5 \%)\end{array}$ & $\begin{array}{l}\text { Attacking PGF or } \\
\text { PG One }(11.09 \%)\end{array}$ \\
\hline 3 & $\begin{array}{c}\text { TVL's } \\
\text { identity }(9.21 \%)\end{array}$ & - & $\begin{array}{c}\text { Onlooker's } \\
\text { reaction }(12.09 \%)\end{array}$ & $\begin{array}{l}\text { Attacking PGF or } \\
\text { PG One }(10 \%)\end{array}$ & $\begin{array}{l}\text { Response to PGF's } \\
\text { action }(10.06 \%)\end{array}$ \\
\hline 4 & Dirty words (7.89\%) & - & $\begin{array}{l}\text { Response to } \\
\text { PGF's action } \\
(10.94 \%)\end{array}$ & $\begin{array}{l}\text { The friendly } \\
\text { army }(8.75 \%)\end{array}$ & $\begin{array}{c}\text { Onlooker's } \\
\text { reaction }(9.91 \%)\end{array}$ \\
\hline 5 & Education (6.58\%) & - & $\begin{array}{l}\text { Deceiving } \\
(6.72 \%)\end{array}$ & $\begin{array}{c}\text { PG One's } \\
\text { candal }(7.5 \%)\end{array}$ & Deceiving (5.92\%) \\
\hline
\end{tabular}

Table 5. Content by each stakeholder group.

The various stakeholder groups differ from each other in the frequency of metaphor use, and the rank of their Top 5 topics (Table 5). As can be seen in Table 5, PGF aimed at maintaining PG One positive image, which they admire, and thus their main focus was whitewashing his actions. TVL only posted on "Gutter oil of TVL" and showed that they are part of "the friendly army". VIP were mainly "reporting the event" progression, saying for example "This topic had been read more than 20 million times” (话题的阅读量突破 2000 万). Interestingly, GP most frequent topics resembles the overall rank of frequent content, perhaps due to the fact that they posted the vast majority of posts during this event.

\section{3) Trolling tactics}

We further analyzed the use of trolling tactics by the five stakeholder groups (Table 6). Because TVL had only one post in our sample, we excluded it from farther analysis. As is shown in Table 6, the most common tactic overall is "Group trolling", followed by "Emotional display", "Lying", "Memes", and "Sarcasm". PDF preferred to use hostile and insulting words to interact with others, such as “Do you have shit in your head?” (你是脑子装大便了吗?), as well as posting “illogical claims”, such as, “What's wrong with taking drugs?” (吸毒怎么了?). GP mainly trolled as part of a group or trolled their target together. They tended to use more dog's head than other groups in reference to "the friendly army", and liked to troll others by adopting “memes” and “sarcasm", such as “Please sit down, Duxiu Chen”(陈独秀, 你坐下). People use this name as a meme just based on the meaning of the last two words: the word "Du" means alone and the word "Xiu" means a show. Nowadays, people refers to Duxiu as someone who show off alone and does not give others a chance; it typically accuses someone to be showing off alone and to be the focus of public attention. VIP users were more likely to troll by "lying" and their trolling involves more “name calling" in reference to PGF. For example, "PG One's brainless fans dare to publicly attack TVL" (PG One 的脑残粉 竟敢公开怤紫光阁), or “Must ban this cult” (封杀这种邪教). The top 5 trolling tactics that GP users exhibited are similar to the overall results, and it might be due to the fact that GP users dominated this event.

\begin{tabular}{|c|c|c|c|c|}
\hline $\begin{array}{c}\text { Tactics by } \\
\text { stakehold- } \\
\text { ers group }\end{array}$ & $\begin{array}{c}\text { PGF } \\
\text { (percent of tactic out } \\
\text { of PGF tactics) }\end{array}$ & $\begin{array}{c}\text { GP } \\
\text { (percent of tactic out of } \\
\text { all GP tactics) }\end{array}$ & $\begin{array}{c}\text { VIP } \\
\text { (percent of tactic out } \\
\text { of all VIP tactics) }\end{array}$ & $\begin{array}{c}\text { Overall } \\
\text { (percent of tactic out of } \\
\text { all tactics) }\end{array}$ \\
\hline $\mathbf{1}$ & Flaming (23.47\%) & Group trolling (15.86\%) & Lying (8.99\%) & Group trolling (13.86\%) \\
\hline $\mathbf{2}$ & $\begin{array}{c}\text { Illogical claim } \\
(10.20 \%)\end{array}$ & $\begin{array}{c}\text { Emotional display } \\
(12.62 \%)\end{array}$ & Name calling (7.87\%) & $\begin{array}{c}\text { Emotional display } \\
(10.02 \%)\end{array}$ \\
\hline $\mathbf{3}$ & Group trolling (8.16\%) & Lying (8.58\%) & Sarcasm (6.74\%) & Lying (7.80\%) \\
\hline $\mathbf{4}$ & Mockery (8.16\%) & Memes (7.77\%) & Mockery (6.74\%) & Memes (6.68\%) \\
\hline $\mathbf{5}$ & Name calling (8.16\%) & Sarcasm (6.47\%) & Group trolling (6.74\%) & Sarcasm (6.44\%) \\
\hline
\end{tabular}

Table 6. Tactics by each stakeholder group 


\section{DISCUSSION AND CONCLUSION}

In this paper, we investigated collective trolling behavior in the Chinese context of Sina Weibo. Results illustrated a wellorganized and well-planned collective trolling when four stakeholder groups assumed different roles, switching between trolls, victims and bystanders. Each group utilized a set of tactics in pursuing their goals. Thus, we argue that our study extends previous understanding of online trolling as an individual behavior (e.g., Fichman \& Sanfilippo, 2016; Shachaf \& Hara, 2010) to understand trolling also as a coordinated group effort. Our finding indicates that in the context of Chinese collectivistic culture, and under perceived lack of online anonymity in China, trolling is not an isolated behaviors of individual trolls, but rather a set of group behaviors. This is much in line with the argument that context, in our case Chinese Sina Weibo, shapes online behaviors (Sanfilippo, Yang \& Fichman, 2017a; Sanfilippo, Yang, \& Fichman, 2017b). Furthermore, our study provides an account of a Chinese trolling event as trolling behaviors vary during the various stages of the event; participants' roles evolve and change, and so do their tactics. Through this Chinese case study, we documented how stakeholders changed roles between trolls, bystanders, and victims during different stages of the event. Users switched roles throughout the same trolling event; a user can post as a troll or a victim of trolls during the same trolling event. Trolling behaviors are complex; not all trolling is anti-social and not all participants assumed the same role throughout the event. Additionally, we found that in the same period and in the same context, members of one stakeholder group may troll each other, just for fun. Thus, while previous research documented how socio-technical context impact online trolling, this paper suggests that trolling is a dynamic process with a range of manifestations within one socio-technical setting, Sina Weibo PG One case study. Clearly the features and context of the technological platform and Chinese socio-cultural norms, together, provide a different representation of the trolling phenomenon.

Future research can aim to gain a better understanding of the evolutionary mechanism of switching role in the same context and examine the interaction between trolls in the same group. In addition, future research can compare and contrast insiders' and outsiders' behavioural tactics in specific trolling events. Finally, future research may compare and contrast the unique attributes of online trolling in the East and West.

In summary, major contributions of this study include an account of 1) collective trolling in Chinese cultural context; 2) role switching between trolls, bystanders, and victims; and 3) an account of trolling event over time. We conclude with suggestions for future research directions.

\section{ACKNOWLEDGMENTS}

Honglei Sun was a visiting PhD candidate at Indiana University, supported by the China Scholarship Council, when this work was performed. We would like to thank Mr. Mitchell Casiano for proofreading and express our special thanks to the reviewers for their constructive suggestions.

\section{REFERENCES}

Bishop, J. (2014). Representations of 'trolls' in mass media communication: a review of media-texts and moral panics relating to internet trolling. International Journal of Web Based Communities, 10(10), 7-24.

China Internet Network Information Center (CNNIC). (2018). 41th statistical report on Internet development in China. China Internet Network Information Center (CNNIC), Beijing, China. Retrieved March 17, 2018 from http://www.cnnic.net.cn/hlwfzyj/hlwxzbg/hlwtjbg/201803/P020180305409870339 136.pdf.

Corbin, J., \& Strauss, A. (2014). Basics of qualitative research: Techniques and procedures for developing grounded theory (4 edition ed.). SAGE Publications, Los Angeles, CA.

Ensafi, R., Winter, P., Mueen, A., \& Crandall, J. R. (2015). Analyzing the Great Firewall of China over space and time. Proceedings on Privacy Enhancing Technologies, 1, 61-76.

Fan, S. (2018). Fans and Netizens React to Rapper PG One's Recent Scandals. Retrieved March 16, 2017 from https://radiichina.com/fansand-netizens-react-to-rapper-pg-ones-recent-scandals/.

Fichman, P., \& Sanfilippo, M. R. (2015). The bad boys and girls of cyberspace: How gender and context impact perception of and reaction to trolling. Social Science Computer Review, 33(2), 163-180.

Fichman, P., \& Sanfilippo, M.R. (2016). Online trolling and its perpetrators: Under the cyberbridge. Lanham: Rowman \& Littlefield Publishers.

Hardaker, C. (2010). Trolling in asynchronous computer-mediated communication: From user discussions to academic definitions. Journal of Politeness Research Language Behaviour Culture, 6(2), 215-242.

Jiang, W., Wang, Y., Tsou, M. H., \& Fu, X. (2015). Using social media to detect outdoor air pollution and monitor air quality index (AQI): A geo-targeted spatiotemporal analysis framework with Sina Weibo (Chinese Twitter). Plos One, 10(10), e0141185.

Herring, S., Job-Sluder, K., Scheckler, R., \& Barab, S. (2002). Searching for safety online: Managing "trolling” in a feminist forum. Information Society, 18(5), 371-384.

Kling, R. (2007). What is social informatics and why does it matter? The Information Society, 23, 205-220. 
Köksal, M. H., \& Riddle, L. (2007). Consumer behaviour and preferences regarding children's clothing in turkey. Journal of Fashion Marketing \& Management, 11(1), 69-81.

Kothari CR. (1990). Research methodology: Methods and techniques. New Delhi: Wishwa Prakashan.

Lin, C., He, J., Zhou, Y., Yang, X., Chen, K., \& Song, L. (2013). Analysis and identification of spamming behaviors in Sina Weibo microblog. The Workshop on Social Network Mining \& Analysis (pp.1-9).

Noonan, K. (2017). Weibo Delivers Second-Quarter Sales and Earnings Beat. Retrieved March 21, 2017 from https://www.fool.com/investing/2017/08/12/weibo-delivers-second-quarter-sales-and-earnings-b.aspx.

Phillips, W. (2015). This is why we can't have nice things: Mapping the relationship between online trolling and mainstream culture. Cambridge, MA: MIT Press.

Sanfilippo, M. R., Yang, S., \& Fichman, P. (2017a). Managing online trolling: From deviant to social and political trolls. Hawaii International Conference on System Sciences (pp.1802-1811).

Sanfilippo, M., Yang, S., \& Fichman, P. (2017b). Trolling here, there, and everywhere: Perceptions of trolling behaviors in context. Journal of the Association for Information Science \& Technology, 68(10): 2313-2327.

Sanfilippo, M. R., Fichman, P., \& Yang, S. (2018). Multidimensionality of online trolling behaviors. Information Society, $34(1)$, 1-13.

Sekaran, U., \& Bougie, R.( 2010). Research Method for Business (5 edition ed). John Wiley and Sons, Inc. USA.

Seta, G. D. (2013). Spraying, fishing, looking for trouble: The Chinese internet and a critical perspective on the concept of trolling. Fibreculture Journal, 22(22): 301-318.

Shachaf, P., \& Hara, N. (2010). Beyond vandalism: Wikipedia trolls. Journal of Information Science, 36(3), 357-370.

Suler, J. (2004). The online disinhibition effect. Cyberpsychol Behavior, 7(3), 321-326.

Suler, J. R., \& Phillips, W. L. (1998). The bad boys of cyberspace: Deviant behavior in a multimedia chat community. Cyberpsychology \& Behavior, 1(3): 275-294.

Sullivan, J. (2013). China's weibo: Is faster different?. New Media \& Society, 16(1), 24-37.

Wang, H., Lei, K., \& Xu, K. (2015). Profiling the followers of the most influential and verified users on Sina Weibo. IEEE International Conference on Communications (pp.1158-1163). IEEE.

Yang, S., Chen, P. Y., Shih, P. C., Bardzell, J., \& Bardzell, S. (2017). Cross-strait frenemies: Chinese netizens VPN in to Facebook Taiwan. Proceedings of the ACM on Human-Computer Interaction 1(CSCW), Article-115.

Yang, S., \& Fichman, P. (2016, September). Collective online trolling: The "Diba Expedition”, 4S/EASST Conference, Barcelona, September, 2016.

$81^{\text {st }}$ Annual Meeting of the Association for Information Science \& Technology | Vancouver, Canada | 10 - 14 November 2018 Author(s) Retain Copyright 